\title{
Three in one: safety, efficacy, and patient acceptability of triple fixed-dose combination medicine in the management of hypertension
}

This article was published in the following Dove Press journal:

Patient Preference and Adherence

31 July 2012

Number of times this article has been viewed

\section{Addison A Taylor \\ Shawn Ragbir}

Department of Medicine, Baylor College of Medicine, Houston, TX, USA
Correspondence: Addison A Taylor Department of Medicine, Baylor College of Medicine, 1709 Dryden Road, Suite 600, MS620, Houston, TX 77030, USA Email ataylor@bcm.edu

\begin{abstract}
Hypertensive patients whose blood pressures are more than $20 \mathrm{mmHg}$ above their goal will often require three or more medications. Careful selection of medications whose actions are complementary or have an improved adverse effect profile when combined can affect not only the blood pressure but also patient acceptance, thus improving persistence in taking the medications as prescribed. This review will highlight the three single-pill three-drug combinations currently available in the US and will address their efficacy, safety, and tolerability. All three include the dihydropyridine calcium-channel blocker, amlodipine, and the thiazide diuretic, hydrochlorothiazide. They each contain a different renin-angiotensin system blocker. One includes the angiotensin-receptor blocker, olmesartan, while another contains valsartan. The third combination includes the direct renin inhibitor, aliskiren. All three fixed-dose combinations (FDC) at maximum doses of each component lowers the blood pressure of patients with stage II hypertension by 37 to $40 \mathrm{mmHg}$ systolic and 21 to $25 \mathrm{mmHg}$ diastolic, which is superior to any two of the components that comprise the three-drug FDC. These drugs are effective in males and females, the elderly, diabetics, minority populations, and patients with metabolic syndrome. Triple-drug FDCs are well tolerated with a low incidence of adverse effects, the most common being peripheral edema related to amlodipine. Extrapolation of data from two-drug FDC suggests that medication compliance (adherence and persistence) should be better with these FDCs than with the individual components taken as separate medications, although additional studies are necessary to confirm this.
\end{abstract}

Keywords: calcium-channel blockers, hypertension, patient tolerability, renin-angiotensin system antagonists, safety, triple-drug combinations

\section{Introduction}

Hypertension is the most prevalent modifiable risk factor for cardiovascular and cerebrovascular morbidity and mortality. An estimated 30\% of the adult population in the United States has hypertension, ${ }^{1}$ and a similar prevalence worldwide represents a global health problem. ${ }^{2}$ The risk of a cardiovascular or cerebrovascular event is closely linked to the magnitude of blood pressure (BP) increase ${ }^{3}$ and is exaggerated at any level of blood pressure in individuals who also have diabetes mellitus, chronic kidney disease, or coronary artery disease..$^{4-9} \mathrm{~A}$ higher BP at the time of diagnosis indicates that he or she is more likely to require two or more drugs to achieve BP control. More drugs will likely be required for individuals with coronary artery disease, chronic kidney disease, or diabetes for whom goals lower than 140/90 $\mathrm{mmHg}$ have been recommended. ${ }^{6,10}$ Furthermore, there is growing evidence from randomized clinical trials such as VALUE (Valsartan Antihypertensive Long-Term Use Evaluation), ${ }^{11}$ Syst-Eur (Systolic 
Hypertension in Europe), ${ }^{12}$ and SHEP (Systolic Hypertension in the Elderly Program) $)^{13}$ to support the benefit of rapid BP reduction, which can be achieved more effectively by initiating combination therapy early rather than by sequentially adding medications.

Egan et al recently reported that the number of subjects who met their definition for both treated but uncontrolled and apparent treatment-resistant hypertension increased during each of three National Health and Nutrition Examination Survey periods between 1988 and 2008. ${ }^{14}$ These are hypertensive subjects that are likely to benefit from at least two and typically three or more carefully selected antihypertensive drugs with complementary mechanisms of action. ${ }^{15,16}$

The true incidence of stage 2 hypertension in the US is not well documented because in large epidemiological surveys, it is often difficult, if not impossible, to obtain BP readings in subjects who are taking no medications. However, it is generally accepted by hypertension experts that an individual with a systolic blood pressure (SBP) $20 \mathrm{mmHg}$ above his or her goal will require at least two drugs to achieve that goal. Anecdotal experience among physicians who treat many hypertensive patients suggests that a patient is likely to require one antihypertensive drug for every $10 \mathrm{mmHg}$ above goal BP. Thus, diabetics, whose average systolic pressure is $170 \mathrm{mmHg}$, may require as many as four carefully chosen and complementary antihypertensive drugs to reduce their SBP to $130 \mathrm{mmHg}$.

Convergence of several concepts in antihypertensive therapy strongly supports the initiation of drug treatment of hypertension with two drugs with complementary mechanisms of action rather than starting with a single drug and adding or substituting a second drug at a later time. There are currently three clinical trials measuring outcomes for which post-hoc analysis of their results support this approach. Cardiovascular events occurred less frequently among patients whose BP was lowered to goal within 6 months of initiating therapy compared to those who required a longer period of time to achieve that goal in the VALUE trial. ${ }^{11,17}$ Similar observations were made during post-hoc analysis of event data from Syst-Eur ${ }^{12,18}$ and SHEP. ${ }^{13,19}$

Essential hypertension is defined in the Joint National Committee on Prevention, Detection, Evaluation, and Treatment of High Blood Pressure (JNC 7) guidelines ${ }^{10}$ as a BP reading of $\geq 140 / 90 \mathrm{mmHg}$ in nondiabetic patients or $\geq 130 / 80 \mathrm{mmHg}$ in those diagnosed with diabetes mellitus and/or receiving antihypertensive medications, is the most important risk factor in cardiovascular and cerebrovascular morbidity and mortality worldwide, contributing to approximately one-half and two-thirds of these diagnoses respectively; an estimated $29 \%$ of the US population carries a diagnosis of hypertension. ${ }^{1}$ For every increase of $20 \mathrm{mmHg}$ and $10 \mathrm{mmHg}$ in SBP and diastolic BP (DBP) respectively, cardiovascular mortality risk approximately doubles from an average pressure of $115 / 75 \mathrm{mmHg}{ }^{3}$ Despite the use of multiple drug classes, success in achieving these absolute goals in the majority has been difficult. Moreover, drug treatment requirements to achieve goal in the ALLHAT trial ${ }^{20,21}$ echoed the observation in the Hypertension Optimal Treatment trial; ${ }^{22}$ nearly one-half required dual therapy, and approximately one-fifth required three or more drugs. In 1997, the JNC-VI recommended combination therapy as a potential choice for treating hypertension refractory to monotherapy. ${ }^{23}$ Based on these findings, Gradman et al published the American Society of Hypertension position paper on combination therapy. Given the significant patient population that remains uncontrolled on dual-drug therapy, three-drug therapy is emerging as a possible alternative.

\section{Historical perspective on single-pill triple-drug combination therapy}

The first triple-drug single-pill combination to be marketed in the US combined reserpine, apresoline, and hydrochlorothiazide. Marketed in the 1950s under the brand name Ser-Ap-Es ${ }^{\circledR}$, elements of this combination were administered to patients in the treatment arm of the first randomized, placebo-controlled VA Cooperative Trial of patients with severe hypertension. ${ }^{24}$ Compared to thousands of hypertensive patients enrolled in recent clinical trials of cardiovascular outcomes in patients receiving two different treatment regimens, a cohort of only 143 subjects, 70 given placebo and 73 given active treatment, with DBPs between 115 and $129 \mathrm{mmHg}$, showed a significant survival benefit within 18 months in favor of the active treatment group in this trial.

Despite the publication of compelling rational arguments in favor of combination therapy by Dollery and others in the $1970 \mathrm{~s},{ }^{25}$ the use of multidrug single-pill combination therapy for treating most hypertensive patients fell out of favor as the "stepped care" approach to treatment became the favored paradigm of hypertension experts; this approach was recommended in the guidelines published in JNC III-IV. ${ }^{26,27}$ The prevailing philosophy in the 1980s was that this approach would reduce overtreatment with consequent hypotension and associated comorbidities and avoid confusion about which of the components in a multidrug combination was linked to a particular adverse effect. In the academic community, most hypertension experts eschewed combination therapy, labeling it as "unnecessary polypharmacy." 28 


\section{Paradigm shift to combination therapy}

The results of clinical trials over the past decade have alerted practicing physicians to the practical necessity of combination therapy to achieve and maintain goal BPs for most patients with hypertension, particularly the $>95 \%$ who have other cardiovascular risk factors. ${ }^{29}$ For example, although approximately $75 \%$ of older patients with high cardiovascular risk in the Antihypertensive and Lipid-Lowering Treatment to Prevent Heart Attack trial ${ }^{30}$ randomized to one of four monotherapies (chlorthalidone, amlodipine, lisinopril, or doxazosin) showed a blood pressure $<140 / 90 \mathrm{mmHg}$ after the first 6 months of treatment, by the end of study follow-up averaging 4.9 years only $30 \%$ remained controlled on a single drug, while $70 \%$ required at least two drugs and approximately $25 \%$ were taking 3 or more drugs. ${ }^{20}$ Similarly, by the time the Anglo-Scandinavian Cardiac Outcomes Trial-Blood Pressure Lowering Arm (ASCOT-BPLA) which compared atenolol \pm bendroflumethiazide with amlodipine \pm perindopril treatment regimens, was stopped after a median follow-up of 5.5 years, $78 \%$ of controlled hypertensive patients were taking at least two drugs to maintain BP control. ${ }^{31}$ In a meta-analysis of 354 randomized, placebo-controlled trials by Law et al, low-dose combinations from the five major classes of antihypertensive drugs (beta-blockers, diuretics, calcium-channel blockers, angiotensin-converting enzyme inhibitors, and angiotensin-receptor blockers) were more effective in reducing BP and exhibited fewer adverse effects than monotherapy. ${ }^{32}$ Although many hypertensive patients can achieve their goal BP with two-drug therapy, there is still a need for effective and safe three-drug regimens for a significant minority of hypertensive patients whose BP is not controlled by two drugs alone.

\section{Triple therapy: rational treatment for hypertension uncontrolled by two drugs}

Three three-drug, single-pill formulations, Tribenzor ${ }^{\circledR}$ (amlodipine + olmesartan + hydrochlorothiazide; Daiichi Sankyo, Inc., Parsippany, NJ), Exforge $\mathrm{HCT}^{\circledR}$ (amlodipine + valsartan + hydrochlorothiazide; Novartis Pharmaceuticals, East Hanover, NJ), and Amturnide ${ }^{\circledR}$ (amlodipine + aliskiren + hydrochlorothiazide; Novartis) are currently approved by the US Food and Drug Administration (FDA) for treating hypertensive patients whose BPs are not controlled by two drugs in the same class as any of the individual components. The efficacy of each of these combinations in reducing BP was evaluated in randomized controlled trials against corresponding combination dual therapy.

The TRINITY (TRIple therapy with olmesartan medoxomil, amlodipine, and hydrochlorothiazide in hyperteNsIve patienTs StudY) trial ${ }^{33}$ screened a cohort of 6724 potentially eligible hypertensive patients with seated mean BPs of $\geq 140 / 90$ on therapy or $\geq 160 / 100$ on no therapy. Of those screened, 2494 were randomized to one of the following four treatment regimens: olmesartan $(\mathrm{OM}) 40 \mathrm{mg}+$ amlodipine (AML) $10 \mathrm{mg}, \mathrm{n}=628$; OM $40 \mathrm{mg}$ + hydrochlorothiazide (HCT) $25 \mathrm{mg}, \mathrm{n}=637$; AML $10 \mathrm{mg}+$ HCT $25 \mathrm{mg}, \mathrm{n}=600$; $\mathrm{OM} 40+\mathrm{AML} 10 \mathrm{mg}+\mathrm{HCT} 25 \mathrm{mg}, \mathrm{n}=627$. To ameliorate the risk of excessive hypotension, a dual-therapy titration scheme was employed for the first 4 weeks of the trial. Treatment then continued for the final 8 weeks on the final combination therapy to which the patient had been assigned. Patients with either active or recent comorbidities such as cerebrovascular or coronary artery disease, congestive heart failure New York Heart Association stage III or IV, stage IV chronic kidney disease, secondary hypertension, chronic atrial fibrillation, heart block worse than 1st degree, symptomatic resting bradycardia, uncontrolled diabetes mellitus (glycosylated hemoglobin $>9 \%$ ), or abnormal laboratory values thought to be clinically significant by the investigator, were excluded.

The baseline demographics of the patients in the four treatment groups were similar. The mean ages were 54.7 to 55.9 years, $51 \%$ to $55.7 \%$ were male, $28.8 \%$ to $32 \%$ were black, $61.7 \%$ to $63.5 \%$ were obese with a mean body mass index ranging from 33 to $33.2 \mathrm{~kg} / \mathrm{m}^{2}, 15.3 \%$ to $15.9 \%$ were diabetic, $20 \%$ to $29 \%$ had chronic kidney disease (creatinine clearance $\geq 30$ but $\leq 60 \mathrm{~mL} / \mathrm{min}$ ), and $55 \%$ to $61 \%$ had chronic stable cardiovascular disease. Baseline seated SBP (SeSBP) was 167.9 to $169 \mathrm{mmHg}$ and seated DBP (SeDBP) was 100.7 to $101.3 \mathrm{mmHg}$. More than $95 \%$ of patients in each group met the JNC 7 criteria $^{10}$ for stage 2 hypertension $(\geq 160 / \geq 100 \mathrm{mmHg}$ ) at baseline. After 12 weeks of therapy, the group receiving triple therapy with $\mathrm{OM}+\mathrm{AML}+\mathrm{HCT}$ achieved greater least squares mean reductions in both SeSBP $(-37.1 \mathrm{mmHg})$ and SeDBP $(-21.8 \mathrm{mmHg})$ than in the dual-therapy groups (SeSBP -27.5 to $-30.0 \mathrm{mmHg}$ and SeDBP -15.1 to $18.0 \mathrm{mmHg}$ ) (Table 1). The proportion of patients reaching a target BP of $<140 / 90$ was also higher in the triple-therapy group (69.9\%) than in the dual-therapy groups $(41.1 \%$ to $53.4 \%)$. Patient persistence in taking study medication was monitored by pill count at each visit; with adherence rates ranging from $98 \%$ to $98.5 \%$ across all treatment groups. 
Table I Comparison of the mean seated systolic and diastolic blood pressure reductions achieved by each of the three FDA-approved single-pill triple-drug combinations and their component two-drug combinations

\begin{tabular}{lllll}
\hline $\begin{array}{l}\text { Drug } \\
\text { combo/max dose }\end{array}$ & Cohort size & $\begin{array}{l}\text { Baseline SBP/DBP } \\
(\mathbf{m m H g})\end{array}$ & $\begin{array}{l}\text { Change in SBP } \\
(\mathbf{m m H g})\end{array}$ & $\begin{array}{l}\text { Change in DBP } \\
(\mathbf{m m H g})\end{array}$ \\
\hline OLM40/AMLI0/HCT25 & & $170 / 101$ & -37 & -22 \\
OLM40/AMLI0 & 627 & $168 / 101$ & -30 & -18 \\
OLM40/HCT25 & 628 & $169 / 101$ & -30 & -17 \\
AMLI0/HCT25 & 637 & $169 / 101$ & -28 & -15 \\
VAL320/AMLI0/HCT25 & 600 & $170 / 106$ & -40 & -25 \\
VAL320/AMLI0 & 583 & $170 / 107$ & -34 & -22 \\
VAL320/HCT25 & 568 & $170 / 106$ & -32 & -20 \\
AMLI0/HCT25 & 559 & $171 / 107$ & -32 & -20 \\
ALI300/AMLI0/HCT25c & 561 & NR/NR* & -38 & -21 \\
ALI300/AMLI0 & 308 & NR/NR* & -31 & -18 \\
ALI300/HCT25 & 282 & NR/NR* & -28 & -14 \\
AMLI0/HCT25 & 296 & NR/NR* & -31 & \\
\hline
\end{tabular}

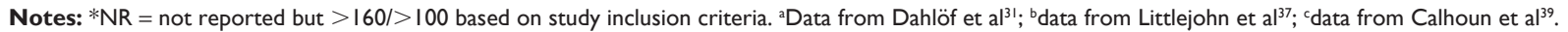
Abbreviations: ALI, aliskiren; AML, amlodipine; HCT, hydrochlorothiazide; OLM, olmesartan; VAL, valsartan.

Both dual and triple drug combinations were well tolerated. The incidence of treatment-emergent adverse events (TEAEs) was comparable among the four groups $(58.4 \%$ for triple-therapy vs $51.7 \%$ to $58.9 \%$ for the dual-therapy groups); most TEAEs were of mild-to-moderate severity and only infrequently resulted in discontinuation of study drug. Discontinuation rates related to study drug, although highest in the triple-therapy group at $3.1 \%$ compared to $0.7 \%$ to $0.9 \%$ in the dual-therapy group, were quite low. The incidence of dizziness was $10 \%$ and $9.9 \%$ in the OM 40/HCT 25 and OM 40/AML10/HCT 25 groups, respectively, compared to $4.9 \%$ and $3.1 \%$ in the OM 40/AML10 and AML10/HCT 25 groups. In contrast, the incidence of reported hypotension was only $2.1 \%$ in the triple-therapy group and $0 \%$ to $0.7 \%$ in the dual-therapy groups. The most common adverse effect of calcium channel blockers is peripheral edema. That observation was confirmed in the Trinity Trial with $7.7 \%$ to $9.8 \%$ of participants receiving AML reporting peripheral edema versus only $1.6 \%$ in the OM $40 / \mathrm{HCT} 25$ group. The most common reason for drug discontinuation in the AML10/HCT 25 group $(0.4 \%)$ was hypokalemia. Other than these TEAEs, which were expected based on the pharmacologic actions of the drugs used in the trial, the authors report no clinically significant drug-related changes in laboratory chemistry or hematological parameters, heart rate, electrocardiograms or physical exam findings.

\section{Trinity subgroup analyses}

Several prespecified subgroup analyses of the Trinity trial data have been conducted and the results either published or reported in abstract form. As noted previously, approximately
15.5\% (387/2492) of the Trinity Study cohort had diabetes mellitus and the proportion of diabetics randomized to each of the 4 treatment groups was comparable (91-99 subjects). ${ }^{34}$ The least squares mean reduction in SeSBP and SeDBP for patients receiving triple-therapy was similar in diabetics and non-diabetics $(-37.9 /-22.0$ vs $-38.5 /-21.5$, respectively) and significantly greater than SeSBP and SeDBP decreases noted in each of the dual-therapy groups. The discrepancy in SeSBP and SeDBP between diabetics and non-diabetics was greatest (-26.7/-14.7 vs $-31.8 /-17.0)$ in the group randomized to OM 40/HCT 25. A slightly smaller percentage of diabetic patients $(64.2 \%)$ in the triple-therapy group achieved a target BP of $<140 / 90$ than nondiabetic patients (70.9\%), but the proportion of diabetics and nondiabetics achieving a BP of $<130 / 80$ was identical (41.8\%).

Efficacy and safety in each of the four treatment groups was analyzed by age and sex and the results were reported in abstract form. Approximately $19 \%$ of the patients were $>65$ years old and there were slightly more men (1318) than women (1174). The same pattern of superior SeSBP and SeDBP reduction with triple therapy compared to each of the dual therapy arms was present irrespective of either age or sex. ${ }^{35}$ As has been demonstrated in numerous previous studies, the extent of BP reduction obtained with either triple- or dual-therapy in the Trinity trial was greatest in those who received the most antihypertensive medications, and in those who had the highest BP values at baseline. ${ }^{36}$ The least squares mean seated BP responses of black $(\mathrm{n}=740, \mathrm{~B})$ and nonblack $(\mathrm{n}=1718, \mathrm{NB})$ patients to either two-drug $(\mathrm{OM} /$ AML, AML/HCT or OM/HCT) or to three-drug (OM/AML/ HCT) therapy were not significantly different, although the 
magnitude of the BP reduction was significantly greater for three-drug therapy $(\mathrm{B}=37.1 / 20.8, \mathrm{NB}=38.9 / 21.8 \mathrm{mmHg})$ than for two-drug treatment $(\mathrm{B}=28.9$ to $30.7 / 14.5$ to $17.0 \mathrm{mmHg}, \mathrm{NB}=28.6$ to $31.9 / 14.8$ to $18.1 \mathrm{mmHg}) .{ }^{37}$ TEAEs were comparable in black and nonblack patients across all four treatment groups.

A Trinity trial ambulatory blood pressure substudy evaluated 24-hour ambulatory blood pressures (ABPM) at baseline and after 12 weeks of therapy in 440 patients from the larger 2492 patient cohort who were randomized to either the triple-therapy combination or one of the three dual-therapy combination groups. ${ }^{38}$ Baseline demographic characteristics of the ABPM substudy cohort had a more varied representation of males, ethnic groups, and diabetics than the full study cohort but very similar SeSBP and SeDBP across the substudy groups and compared to the treatment group distribution in the full study cohort. The ABPM results confirmed that triple-drug combination was more effective in lowering 24-hour mean BP $(-30.3 /-18.0 \mathrm{mmHg})$ than each of the dual-therapy combinations $(-18.5$ to $23.9 \mathrm{mmHg} /-10.7$ to $-14.5 \mathrm{mmHg})$. There was also greater $\mathrm{BP}$ reduction during the daytime ( 8 am to $4 \mathrm{pm}$ ) and nighttime (10 pm to $6 \mathrm{am}$ ) with the triple-drug combination. Furthermore, significantly more patients taking the three-drug combination achieved 24-hour (86.5\%), daytime (67.3\%), and nighttime (93.3\%) ambulatory BP targets of $<130 / 80 \mathrm{mmHg}$ than those on any of the two-drug component combinations (range $41.9 \%$ to $81.1 \%$ ).

The antihypertensive efficacy and safety of the Exforge$\mathrm{HCT}^{\circledR}$ triple-therapy combination of valsartan $320 \mathrm{mg}$ (V) + amlodipine $10 \mathrm{mg}$ (AML) + hydrochlorothiazide $25 \mathrm{mg}$ (HCT) was compared against its dual therapy components at corresponding doses (VAL + AML, AML + HCT, $\mathrm{VAL}+\mathrm{HCT}$ ) in a randomized, double-blind clinical trial..$^{39} \mathrm{Of}$ the 4285 patients with moderate to severe hypertension (mean $\mathrm{SeSBP} / \mathrm{SeDBP} \geq 145 / \geq 100 \mathrm{mmHg}$ ) who were enrolled in the trial, 2271 were randomized to one of the four drug treatment groups, and 2060 completed the 9 weeks of active treatment. To allow patient adaptation to full dose tripletherapy, half the dose of each drug in either the triple-therapy or dual-therapy component combinations were administered for the first 2 weeks of active therapy, then full doses were given from weeks 3 to 9. Drug doses for each of the four treatment groups were AML10/HCT 25, VAL320/HCT 25, AML10/VAL320, and AML10/VAL320/HCT 25. Of the 2271 patients randomized to the double-blind phase of the trial, 583 were assigned to AML/VAL/HCT, 559 to VAL/HCT, 568 to AML/VAL, and 561 to AML/HCT. Most demographic characteristics, including sex distribution (55\% men), age (mean $=53$ years old), proportion that were $\geq 65$ years old (14\%), diabetes (10\%), and ethnicity (17\% black and $26 \%$ Hispanic) were similar across all treatment groups. Least squares mean SeSBP/SeDBP for the entire cohort was $169.9 / 106.5 \mathrm{mmHg}$. The reduction in SeSBP/SeDBP from baseline to the end of the study in the triple-therapy group was significantly greater $(-39.7 /-24.7 \mathrm{mmHg})$ compared to values in the each of the component dual-therapy groups $(-31.5$ to $-33.5 /-19.5$ to $21.5 \mathrm{mmHg}$ ) (Table 1$)$. Most of the decline in BP had occurred by week 5 of active treatment in all groups. The proportion of patients achieving target BP goals was not reported. A 24-hour ABPM study was conducted in a 283-patient subset of the larger cohort and the results confirmed the superiority of the triple-drug combination in reducing BP more than each of the dualcomponent drug combinations throughout the entire 24-hour monitoring period. ${ }^{40}$

The third triple-drug single-pill combination approved in the US for treating patients whose BPs are not controlled by any two of its components is a combination of the direct renin inhibitor, aliskiren (ALI), combined with amlodipine and HCT (ALI/AML/HCT), which is marketed in the US as Amturnide ${ }^{\circledR}$. Although this three-drug combination was approved by the FDA in December of 2010, limited information about this combination appears in peer-reviewed literature. The data reported in this review from the largest trial of this three-drug combination versus its individual two-drug components (NCT00765674) are derived from the ClinicalTrials.gov website. ${ }^{41}$ The efficacy and safety of ALI/ AML/HCT in patients with moderate to severe hypertension was examined in 1191 subjects randomized to receive ALI/ AML (287 subjects), ALI/HCT (298 subjects), AML/HCT (296 subjects), and ALI/AML/HCT (310 subjects). The mean age of the participants ranged from 54.4 to 55.4 years across the four groups; $19 \%$ were age 65 or older and $60 \%$ were male. Patients in each group were given half the maximum doses for 4 weeks and then force-titrated to ALI $300 \mathrm{mg} / \mathrm{AML} 10 \mathrm{mg}$, ALI 300 mg/HCT 25 mg, ALM 10 mg/HCT 25 mg, and ALI $300 \mathrm{mg} / \mathrm{AML} 10 \mathrm{mg} / \mathrm{HTC} 25 \mathrm{mg}$ for the remaining 4 weeks of the trial. The mean seated office BP was not provided. The reduction in mean seated office systolic/diastolic BP from baseline to week 8 in group order as listed above were $-31 /-18$, $-28 /-14,-31 /-17$, and $-38 /-21 \mathrm{mmHg}$, respectively (Table 1). Using an arbitrary BP control value of $<140 /<90 \mathrm{mmHg}$ for all participants, including diabetics, $41 \%, 33 \%, 39 \%$, and $62 \%$ of patients in each of the four groups were controlled at the end of 8 weeks of active treatment, respectively. A subset of 
576 patients had evaluable 24-hour ABPM data at both baseline and after 8 weeks of treatment. The average reductions in mean 24-hour SBP/DBP in the four groups, in the order listed above, were $-20 /-13,-16 /-10,-19 /-11$, and $-25 /-16 \mathrm{mmHg}$. Serious adverse events were reported in three, two, and two patients in the dual-therapy groups and in six patients in the triple-therapy group, respectively. Events in this last group included one patient with syncope, one patient with excessive BP elevation, one patient with psychosomatic disease, one patient with acute coronary syndrome, one patient with supraventricular arrhythmia, and one patient who developed a thyroid goiter. The most common adverse event was peripheral edema, occurring in $4 \%-8 \%$ of participants taking combinations that included amlodipine vs $2 \%$ in those receiving ALI/ HCT. The second most common AE was headache reported in 3\%-5\% of participants in all treatment groups. Generally, adverse events were mild-to-moderate in all treatment groups and usually did not result in discontinuation of study drug.

The Aliskiren/Amlodipine/Hydrochlorothiazide Versus Aliskiren/Amlodipine in US Minority Patients With Stage II Systolic Hypertension trial randomized 412 self-identified minority patients with stage II hypertension to either a treatment regimen of ALI $300 \mathrm{mg} / \mathrm{AML} 10 \mathrm{mg} / \mathrm{HCT} 25 \mathrm{mg}$ (203 subjects) or ALI $300 \mathrm{mg} / \mathrm{AML} 10 \mathrm{mg}$ (209 subjects). ${ }^{42}$ Black patients comprised 62\%, Hispanics/Latinos 27\%-29\%, and other minorities $9 \%-10 \%$ of those randomized. The average age was 55 years old, $15 \%-18 \%$ of patients were $\geq 65$ years old, 26\%-31\% were diabetic, and body mass index was $32 \%$ in each treatment group. Baseline seated SBP/DBP was $167 / 95 \mathrm{mmHg}$ in both groups, whereas the baseline 24-hour ABPM SBP/DBP was 148/87 mmHg in the triple-therapy subgroup of 112 and $149 / 88 \mathrm{mmHg}$ in the dualtherapy subgroup of 114. Therapy was initiated with lower doses of each of these drugs during the first 4 weeks of the trial, but was force-titrated to the doses noted above for the last 4 weeks of the trial. After 8 weeks of treatment, mean seated SBP/DBP had decreased by 36.4/15.2 mmHg with triple-therapy and 29.5/12.1 with dual-therapy; differences in $\mathrm{BP}$ reduction between the two therapeutic regimens was statistically significant. Subgroup analyses of systolic BP reduction based on sex, age, mean seated SBP at baseline, presence or absence of diabetes, or metabolic syndrome mirrored the differences in the three- versus two-drug arms for the entire cohort, whereas changes in mean seated DBP in some subgroups were not always statistically significant, even though the pattern of differences was similar. Surprisingly, 24-hour ambulatory SBP decreased by $23 \mathrm{mmHg}$ with ALI/AML/ HCT and by $21 \mathrm{mmHg}$ with ALI/AML, a difference that was not statistically or clinically significant. The most common adverse events in these minority hypertensive patients were similar to those reported in NCT00765674 although the incidence of peripheral edema was only $2 \%-3 \%$ in these patients, even though all were taking amlodipine.

A 28-54-week long-term safety study of the tripledrug combination in patients with essential hypertension (NCT00667719) was completed in October of 2009, but no study findings have been published or presented on the ClinicalTrials.gov website. ${ }^{43}$ The ALTITUDE study, ${ }^{44}$ an outcomes trial that randomized diabetic patients with chronic kidney disease already taking an angiotensin-convertingenzyme inhibitor or angiotensin receptor blocker to either aliskiren or placebo, was discontinued early because of an increase in stroke, hypotension, hyperkalemia, and worsening renal function in this high-risk patient population. Consequently, Novartis and the FDA are carefully reviewing the safety data with aliskiren when taken with other antihypertensive medications; the fate of combination products that contain aliskiren is uncertain.

As noted above, a small proportion of hypertensive patients will not achieve the goal BP with a three-drug combination. Although an in-depth review is beyond the scope of this publication, some trials have examined the effects of four-drug therapy on BP and adverse effects. In the $1980 \mathrm{~s}$, a limited number of studies compared the control of BP of patients with resistant hypertension using four drugs that included a diuretic, beta-blocker, hydralazine, and nifedipine with drugs such as minoxidil and diazoxide. ${ }^{45}$ While BP could be reduced, the drugs were poorly tolerated. More recently, a proof-of-concept study demonstrated that a single pill containing a quarter of the single-pill dose of four antihypertensive medications (atenolol, bendroflumethiazide, amlodipine, and captopril) was more effective in reducing BP than any of the single drugs at full dose. ${ }^{46}$ Additional studies will be required to comprehensively evaluate the potential advantages of a four-drug combination pill.

\section{Multidrug therapy: advantages of single-pill combinations}

Numerous retrospective and few prospective analyses report improved patient compliance with taking fixed-dose combination (FDC) medications compared to those same medications prescribed as individual components (IC), irrespective of the therapeutic rationale for prescribing the medications. ${ }^{47-50}$ More than a decade ago, Dezii reported that medication persistence after one year was approximately 
$20 \%$ greater in hypertensive patients prescribed single-pill combinations of either lisinopril/HCT or enalapril/HCT than when the angiotensin-converting-enzyme inhibitor and a diuretic were prescribed separately. ${ }^{51}$ Since then, comparisons of other antihypertensive FDC vs IC have included an evaluation of two but not all three of the components of the triple-drug therapies cited in this review. Better medication compliance with the FDCs of valsartan/amlodipine ${ }^{52}$ and of valsartan $/ \mathrm{HCT}^{53}$ than with their respective ICs has been reported, whereas compliance has not been formally evaluated with two-drug combinations versus free components of ALI/AML/HCT or OLM/AML/HCT. However, it remains unclear whether medication persistence translates into better BP control, reduced adverse effects, and reduced health care costs.

In a recently published meta-analysis of five studies examining drug compliance in 17,999 hypertensive patients taking FDC or IC, FDCs were associated with $21 \%$ better compliance but with only 4.1/3.1 $\mathrm{mmHg}$ lower SBP/DBP and no significant reduction in adverse events. ${ }^{54}$ Whether increased medication compliance with FDC will ultimately be associated with reduced cardiovascular events is currently unknown.

Retrospective analyses of large health systems provider databases have reported that not only does treatment of hypertensive patients with two-drug FDC improve persistence in taking medications compared to IC, but is also associated with decreases in healthcare utilization costs. ${ }^{55,56}$ In their meta-analysis of 12 retrospective database studies, allcause and hypertension-related health care costs were on average $\$ 1357$ lower for patients prescribed FDC than those prescribed IC. ${ }^{55}$ As a confounding factor, racial disparity in both medication compliance and in health care costs has been reported. Dickson and Plauschinat conducted a retrospective examination of both medication compliance and healthcare utilization among African American and Caucasian Medicaid recipients prescribed amlodipine/benazepril FDC versus a $\mathrm{CCB}+$ angiotensin-converting-enzyme inhibitor as an IC. ${ }^{57}$ Although medication compliance was higher with FDC than IC in both ethnic groups, compliance rates were 55\% in African American patients and 61\% in Caucasian patients. Total healthcare service costs were much lower for all patients taking FDC (\$4605) than IC (\$8531), but higher for African American than for Caucasian patients, while drug costs were higher for Caucasian than African American patients. It has also been noted that medication persistence and adherence declines as patient co-payment for FDC and IC drugs increases. ${ }^{58}$

\section{Summary}

Three-drug single-pill fixed-dose combinations expand the options for effectively treating hypertensive patients with stage II hypertension who have not attained goal BPs with two drugs. In clinical trials, the reduction in both SBP and DBP is remarkably similar (Table 1). Each of these fixed dose 3-drug combinations appear to be equally effective in reducing BP toward if not to recommended goals in both sexes, in African Americans and Hispanic/Latino minorities, in the elderly, in diabetics, and in obese/overweight patients with metabolic syndrome with minimal adverse effects. Extrapolation of data from two-drug FDC suggests that medication compliance (adherence and persistence) is better with these FDCs than with the ICs taken as separate medications, although this has yet to be rigorously evaluated. An unanswered question is whether major adverse clinical events will be reduced when FDC rather than IC are prescribed.

\section{Disclosure}

The authors report no conflicts of interest in this work.

\section{References}

1. Roger VL, Go AS, Lloyd-Jones DM, et al. Heart disease and stroke statistics - 2012 update: a report from the American Heart Association. Circulation. 2012;125(1):e2-e220.

2. Kearney PM, Whelton M, Reynolds K, Muntner P, Whelton PK, He J. Global burden of hypertension: analysis of worldwide data. Lancet. 2005;365(9455):217-223.

3. Lewington S, Clarke R, Qizilbash N, et al. Age-specific relevance of usual blood pressure to vascular mortality: a meta-analysis of individual data for one million adults in 61 prospective studies. Lancet. 2002;360(9349):1903-1913.

4. Verdecchia P, Reboldi G, Angeli F, et al. Adverse Prognostic Significance of New Diabetes in Treated Hypertensive Subjects. Hypertension. 2004;43:01.

5. Stamler J, Vaccaro O, Neaton JD, Wentworth D. Diabetes, other risk factors, and 12-yr cardiovascular mortality for men screened in the Multiple Risk Factor Intervention Trial. Diabetes Care. 1993;16(2):434 444.

6. Rosendorff C, Black HR, Cannon CP, et al. Treatment of hypertension in the prevention and management of ischemic heart disease: a scientific statement from the American Heart Association Council for High Blood Pressure Research and the Councils on Clinical Cardiology and Epidemiology and Prevention. Circulation. 2007;115(21):2761-2788.

7. Klag MJ, Whelton PK, Randall BL, Neaton JD, Brancati FL, Stamler J. End-stage renal disease in African-American and white men: 16-year MRFIT findings. JAMA. 1997;277(16):1293-1298.

8. Brancati FL, Whelton PK, Randall BL, Neaton JD, Stamler J, Klag MJ Risk of end-stage renal disease in diabetes mellitus: a prospective cohort study of men screened for MRFIT. Multiple Risk Factor Intervention Trial. JAMA. 1997;278(23):2069-2074.

9. Young JH, Klag MJ, Muntner P, Whyte JL, Pahor M, Coresh J. Blood pressure and decline in kidney function: findings from the Systolic Hypertension in the Elderly Program (SHEP). JAm Soc Nephrol. 2002; 13(11):2776-2782.

10. Chobanian A, Bakris GL, Black HR, et al. The Seventh Report of the Joint National Committee on Prevention, Detection, Evaluation, and Treatment of High Blood Pressure: the JNC 7 report. JAMA. 2003;289(19):2560-2572. 
11. Julius S, Kjeldsen S, Weber M, et al. Outcomes in hypertensive patients at high cardiovascular risk treated with regimens based on valsartan or amlodipine: the VALUE randomised trial. Lancet. 2004;363(9426):2022-2031.

12. Staessen JA, Thijisq L, Fagard R, et al. Effects of immediate versus delayed antihypertensive therapy on outcome in the Systolic Hypertension in Europe Trial. J Hypertens. 2004;22(4):847-857.

13. Kostis JB, Cabrera J, Cheng JQ, et al. Association between chlorthalidone treatment of systolic hypertension and long-term survival. JAMA. 2011;306(23):2588-2593.

14. Egan BM, Zhao Y, Axon RN, Brzezinski WA, Ferdinand KC. Uncontrolled and apparent treatment resistant hypertension in the United States, 1988 to 2008. Circulation. 2011;124(9):1046-1058.

15. Gradman AH, Basile JN, Carter BL, Bakris GL. Combination therapy in hypertension. J Am Soc Hypertens. 2010;4(2):90-98.

16. Gradman AH. Rationale for triple-combination therapy for management of high blood pressure. J Clin Hypertens (Greenwich). 2010;12(11):869-878.

17. Weber M, Julius S, Kjeldsen S, et al. Blood pressure dependent and independent effects of antihypertensive treatment on clinical events in the VALUE Trial. Lancet. 2004;363(9426):2049-2051.

18. Staessen JA, Fagard R, Thijs L, et al. Randomised double-blind comparison of placebo and active treatment for older patients with isolated systolic hypertension. The Systolic Hypertension in Europe (Syst-Eur) Trial Investigators. Lancet. 1997;350(9080):757-764.

19. SHEP Coop Res Group. Prevention of stroke by antihypertensive drug treatment in older persons with isolated systolic hypertension. Final results of the Systolic Hypertension in the Elderly Program (SHEP). SHEP Cooperative Research Group. JAMA. 1991;265(24):3255-3264.

20. Cushman WC, Ford CE, Cutler JA, et al. Success and predictors of blood pressure control in diverse North American settings: the antihypertensive and lipid-lowering treatment to prevent heart attack trial (ALLHAT). J Clin Hypertens (Greenwich). 2002;4(6):393-404.

21. Cushman WC, Ford CE, Einhorn PT, et al. Blood pressure control by drug group in the Antihypertensive and Lipid-Lowering TReatment to Prevent Heart Attack Trial (ALLHAT). J Clin Hypertens (Greenwich). 2008;10(10):751-760.

22. Hansson L, Zanchetti A, Carruthers SG, et al. Effects of intensive bloodpressure lowering and low-dose aspirin in patients with hypertension: principal results of the Hypertension Optimal Treatment (HOT) randomised trial. HOT Study Group. Lancet. 1998;351(9118):1755-1762.

23. Sheps SG, Black HR, Cohen JD, et al. The Sixth Report of the Joint National Committee on Prevention, Detection, Evaluation, and Treatment of High Blood Pressure. Arch Int Med. 1997;157:2413-2446.

24. VA Cooperative Study Group. Effects of treatment on morbidity in hypertension. Results in patients with diastolic blood pressures averaging 115 through $129 \mathrm{mmHg}$. JAMA. 1967;202(11):1028-1034.

25. Dollery CT. Pharmacological basis for combination therapy of hypertension. Annu Rev Pharmacol Toxicol. 1977;17:311-323.

26. The 1984 Report of the Joint National Committee on Detection, Evaluation, and Treatment of High Blood Pressure. Arch Intern Med. 1984;144(5):1045-1057.

27. 1988 Joint National Committee. The 1988 report of the Joint National Committee on detection, evaluation, and treatment of high blood pressure. Arch Intern Med. 1988;148:1023-1038.

28. Kaplan N. Low dose combinations in the treatment of hypertension: theory and practice. J Hum Hypertens. 1999;13(10):707-710.

29. Stern N, Grosskopf I, Shapira I, et al. Risk factor clustering in hypertensive patients: impact of the reports of NCEP-II and second joint task force on coronary prevention on JNC-VI guidelines. J Intern Med. 2000;248(3):203-210.

30. The ALLHAT officers and coordinators for the ALLHAT Collaborative Research Group. Major outcomes in high-risk hypertensive patients randomized to angiotensin-converting enzyme inhibitor or calcium channel blocker vs diuretic: The Antihypertensive and Lipid-Lowering Treatment to Prevent Heart Attack Trial (ALLHAT). JAMA. 2002;288(23):2981-2997.
31. Dahlöf B, Sever PS, Poulter NR, et al. Prevention of cardiovascular events with an antihypertensive regimen of amlodipine adding perindopril as required versus atenolol adding bendroflumethiazide as required, in the Anglo-Scandinavian Cardiac Outcomes Trial-Blood Pressure Lowering Arm (ASCOT-BPLA): a multicentre randomised controlled trial. Lancet. 2005;366(9489):895-906.

32. Law MR, Wald NJ, Morris JK, Jordan RE. Value of low dose combination treatment with blood pressure lowering drugs: analysis of 354 randomised trials. BMJ. 2003;326(7404):1427-1434.

33. Oparil S, Melino M, Lee J, Fernandez V, Heyrman R. Triple therapy with olmesartan medoxomil, amlodipine besylate, and hydrochlorothiazide in adult patients with hypertension: The TRINITY multicenter, randomized, double-blind, 12-week, parallel-group study. Clin Ther. 2010;32(7):1252-1269.

34. Chrysant SG, Izzo JL, Kereiakes DJ, et al. Efficacy and safety of triple-combination therapy with olmesartan, amlodipine, and hydrochlorothiazide in study participants with hypertension and diabetes: a subpopulation analysis of the TRINITY study. J Am Soc Hypertens. 2012;6(2)132-141.

35. Chrysant SG, Melino M, Fernandez V, Lee J, Heyrman R. Efficacy and safety of olmesartan medoxomil $(\mathrm{OM})+$ amlodipine (AML) + hydrochlorothiazide(HCTZ) in patients with hypertension analyzed by age and gender: The Trinity Study: Pp 5.185 [Abstract]. J Hypertens. 2010;28[e-supplement A]:e103.

36. Kereiakes D, Chrysant SG, Melino M, Fernandez V, Lee J. Efficacy and safety of combination olmesartan medoxomil $(\mathrm{OM})+$ amlodipine besylate(AML) + hydrochlorothiazide (HCTZ) based on severity of hypertension: The Trinity Study: PP.5.164 [Abstract]. J Hypertens. 2010;28[e-supplement A]:e97.

37. Littlejohn T, Melino M, Fernandez V, Lee J, Heyrman R. Efficacy and safety of combiantion olmesartan medoxomil (OM) + amlodipine besylate (AML) + hydrochlorothiazide (HCTZ) based on race: The Trinity Study: Pp. 5.172 [Abstract]. J Hypertens. 2010;28[e-supplement A]: e99-e100.

38. Izzo JL Jr, Chrysant GS, Kereiakes DJ, et al. 24-Hour efficacy and safety of Triple-Combination Therapy With Olmesartan, Amlodipine, and Hydrochlorothiazide: The TRINITY ambulatory blood pressure substudy. J Clin Hypertens (Greenwich). 2011;13(12):873-880.

39. Calhoun DA, Lacourciere Y, Chiang YT, Glazer RD. Triple antihypertensive therapy with amlodipine, valsartan, and hydrochlorothiazide: a randomized clinical trial. Hypertension. 2009;54(1):32-39.

40. Lacourcière Y, Crikelair N, Glazer RD, Yen J, Calhoun DA. 24-Hour ambulatory blood pressure control with triple-therapy amlodipine, valsartan and hydrochlorothiazide in patients with moderate to severe hypertension. J Hum Hypertens. 2011;25(10):615-622.

41. Novartis. Efficacy and safety of aliskiren/amlodipine/hydrochlorothiazide in patients with moderate-severe hypertension. In: ClinicalTrials. gov [website on the Internet]. Bethesda, MD: US National Library of Medicine; 2008 [updated April 15, 2011]. Available from: http://clinicaltrials.gov/ct2/show/NCT00765674?term=NCT00765674\&rank=1. NLM identifier: NCT00765674. Accessed May 11, 2012.

42. Ferdinand KC, Weitzman R, Israel M, et al. Efficacy and safety of aliskiren-based dual and triple combination therapies in US minority patients with stage 2 hypertension. J Am Soc Hypertens. 2011;5(2):102-113.

43. Novartis. A long term safety study to test the combination of aliskiren/ amlodipine/hydrochlorothiazide in patients with essential hypertension. In: ClinicalTrials.gov [website on the Internet]. Bethesda, MD: US National Library of Medicine; 2008 [updated August 22, 2011]. Available from: http://clinicaltrials.gov/ct2/show/NCT00667719?term=NC T00667719\&rank=1. NLM identifier: NCT00667719. Accessed May 12, 2012.

44. Parving HH, Brenner BM, McMurray JJ, et al. Aliskiren Trial in Type 2 Diabetes Using Cardio-Renal Endpoints (ALTITUDE): rationale and study design. Nephrol Dial Transplant. 2009;24(5):1663-1671.

45. Swales JD, Bing RF, Heagerty A, et al. Treatment of refractory hypertension. Lancet. 1982;1(8277):894-896. 
46. Mahmud A, Feely J. Low-dose quadruple antihypertensive combination: more efficacious than individual agents-a preliminary report. Hypertension. 2007;49(2):272-275.

47. Bangalore S, Kamalakkannan G, Parkar S, Messerli FH. Fixed-dose combinations improve medication compliance: a meta-analysis. Am J Med. 2007;120(8):713-719.

48. Lummis HL, Sketris IS, Gubitz GJ, Joffres MR, Flowerdew GJ. Medication persistence rates and factors associated with persistence in patients following stroke: a cohort study. BMC Neurol. 2008;8:25.

49. Patel BV, Leslie RS, Thiebaud P, et al. Adherence with single-pill amlodipine/atorvastatin vs a two-pill regimen. Vasc Health Risk Manag. 2008;4(3):673-681.

50. Melikian C, White TJ, Vanderplas A, Dezii CM, Chang E. Adherence to oral antidiabetic therapy in a managed care organization: A comparison of monotherapy, combination therapy, and fixed-dose combination therapy. Clin Ther. 2002;24(3):460-467.

51. Dezii CM. A retrospective study of persistence with single-pill combination therapy vs concurrent two-pill therapy in patients with hypertension. Manag Care. 2000;10(Suppl 10):6-10.

52. Baser O, Andrews LM, Wang L, Xie L. Comparison of real-world adherence, healthcare resource utilization and costs for newly initiated valsartan/amlodipine single-pill combination versus angiotensin receptor blocker/calcium channel blocker free-combination therapy. J Med Econ. 2011;14(5)576-583.
53. Brixner DI, Jackson KC 2nd, Sheng X, Nelson RE, Keskinaslan A. Assessment of adherence, persistence, and costs among valsartan and hydrochlorothiazide retrospective cohorts in free-and fixed-dose combinations. Curr Med Res Opin. 2008;24(9):2597-2607.

54. Gupta AK, Arshad S, Poulter NR. Compliance, safety, and effectiveness of fixed-dose combinations of antihypertensive agents: a meta-analysis. Hypertension. 2010;55(2):399-407.

55. Sherrill B, Halpern M, Khan S, Zhang J, Panjabi S. Single-pill vs freeequivalent combination therapies for hypertension: a meta-analysis of health care costs and adherence. J Clin Hypertens (Greenwich). 2011;13(12):898-909.

56. Taylor AA, Shoheiber O. Adherence to antihypertensive therapy with fixed-dose amlodipine besylate/benazepril $\mathrm{HCl}$ versus comparable component-based therapy. Congest Heart Fail. 2003;9(6):324-332.

57. Dickson M, Plauschinat CA. Racial differences in medication compliance and healthcare utilization among hypertensive Medicaid recipients: fixed-dose vs free-combination treatment. Ethn Dis. 2008; 18(2):204-209.

58. Zeng F, Patel BV, Andrews L, Frech-Tamas F, Rudolph AE. Adherence and persistence of single-pill $\mathrm{ARB} / \mathrm{CCB}$ combination therapy compared to multiple-pill ARB/CCB regimens. Curr Med Res Opin. 2010;26(12):2877-2887.
Patient Preference and Adherence

\section{Publish your work in this journal}

Patient Preference and Adherence is an international, peer-reviewed, open access journal focusing on the growing importance of patient preference and adherence throughout the therapeutic continuum. Patient satisfaction, acceptability, quality of life, compliance, persistence and their role in developing new therapeutic modalities and compounds to

\section{Dovepress}

optimize clinical outcomes for existing disease states are major areas of interest. This journal has been accepted for indexing on PubMed Central. The manuscript management system is completely online and includes a very quick and fair peer-review system. Visit http://www.dovepress.com/ testimonials.php to read real quotes from published authors. 